PO059

\title{
PHYSICAL INDICES FOR REPRESENTING MATERIAL PERCEPTION WITH REGARD TO GLOSSINESS, TRANSPARENCY, AND ROUGHNESS
}

Midori Tanaka et al.

DOI 10.25039/x46.2019.PO059

from

CIE x046:2019

Proceedings

of the

29th CIE SESSION

Washington D.C., USA, June 14 - 22, 2019

(DOI 10.25039/x46.2019)

The paper has been presented at the 29th CIE Session, Washington D.C., USA, June 14-22, 2019. It has not been peer-reviewed by CIE.

(c) CIE 2019

All rights reserved. Unless otherwise specified, no part of this publication may be reproduced or utilized in any form or by any means, electronic or mechanical, including photocopying and microfilm, without permission in writing from CIE Central Bureau at the address below. Any mention of organizations or products does not imply endorsement by the CIE.

This paper is made available open access for individual use. However, in all other cases all rights are reserved unless explicit permission is sought from and given by the CIE.

CIE Central Bureau

Babenbergerstrasse 9

A-1010 Vienna

Austria

Tel.: +4317143187

e-mail: ciecb@cie.co.at

www.cie.co.at 


\title{
PHYSICAL INDICES FOR REPRESENTING MATERIAL PERCEPTION WITH REGARD TO GLOSSINESS, TRANSPARENCY, AND ROUGHNESS
}

\author{
Tanaka, M. ${ }^{1}$, Osumi, M. ${ }^{2}$, Horiuchi, T. ${ }^{1}$ \\ ${ }^{1}$ Chiba University, Chiba, JAPAN, ${ }^{2}$ Office Color Science Co., Ltd., Yokohama, JAPAN \\ midori@chiba-u.jp
}

DOI 10.25039/x46.2019.PO059

\begin{abstract}
The final goal of this study is to build a total appearance model for human perception of the qualities of a material. To achieve this objective, we propose physical indices for modelling perception with regard to glossiness, transparency, and roughness by investigating the relationship between measurable physical properties and the appearance of real materials in this study. In our physical measurements and subjective evaluations, we used 34 stimuli exemplifying ten material categories. As a result, we found physical indices corresponding to subjective perception as follows: (1) The index of perceptual gloss correlates to a nonlinear transform of physical glossiness. (2) The index of perceptual transparency corresponds to the luminance difference of material surfaces with white vs black backgrounds. (3) The index of perceptual roughness correlates to the edge intensity detected from the captured images.
\end{abstract}

Keywords: Total appearance, Glossiness, Transparency, Roughness, Psychometric evaluation, Physical measurement

\section{Introduction}

In addition to colour recognition, evolution has given us various other abilities for instant recognition of object qualities through sight. In the field of imaging science and technology, the study of the material appearance of objects has been actively discussed with consideration of the visual appearance information including factors such as surface texture in addition to colour. In our previous study, we investigated the perceptual appearance of materials obtained from real objects and their rendered images by conducting psychometric experiments. If perceptual characteristics can be estimated by physical measurements, human material perception can be effectively predicted without such psychometric experiments. Moreover, the establishment of new perceptual models and formulae is desirable for correctly representing the total perceptual appearance of real objects. Our specific objective is to find effective physical indices by analysing the relationship between physical qualities and the perceptual appearance.

\section{Stimuli}

In this study, we prepared a dataset of 34 stimuli (size: $50 \mathrm{~mm} \times 50 \mathrm{~mm}$ ) selected from 10 material categories-stone, metal, glass, plastic, leather, fabric, paper, wood, ceramic, and rubber-thereby covering a wide range of material appearances. Figure 1 shows all the materials with their names. Each category included two or more specific stimuli. A previous study (Albertazzi et al., 2013) showed that colour has a strong influence on perceptual qualities. Therefore, we tried to collect specific stimuli with low colour saturation.

\section{Psychometric Evaluations}

We used data from psychometric evaluations (Tanaka et al., 2015), which investigated the perceptual appearance of various materials using the same real materials as shown in Fig. 1.

\subsection{Method}

In the experiment, the participants were asked to make judgments based on the perceptual qualities of real materials. Figure 2 shows the experimental environment using a viewing booth (Macbeth Judge II) with a CIE D65 Average North Sky Daylight. The inside of the viewing booth was covered with low-gloss black felt. The viewing distance was $300 \mathrm{~mm}$, and the viewing angle 
was always $0^{\circ}$. The distance from the light source to the centre of the material was $230 \mathrm{~mm}$ and the stimulus was placed at an inclination angle of $5^{\circ}$ to the vertical direction. The observers evaluated the perceptual glossiness, transparency, and roughness using a 6-point scale [0-5] for each stimulus in the real material dataset. The procedure of the experiment followed that of the conventional report (Fleming et al. 2013). Ten participants, nine males and one female, participated in this experiment. All the experiments were conducted in accordance with The Code of Ethics of the World Medical Association (Declaration of Helsinki).

\subsection{Results}

All the observers had normal colour vision and enough visual power to judge the appearance of the material surface. Most of our results were identical to Fleming's study, but there were some significant differences. Our study included some less conventional stimuli such as hologram coated paper, silver coated paper, and satin.
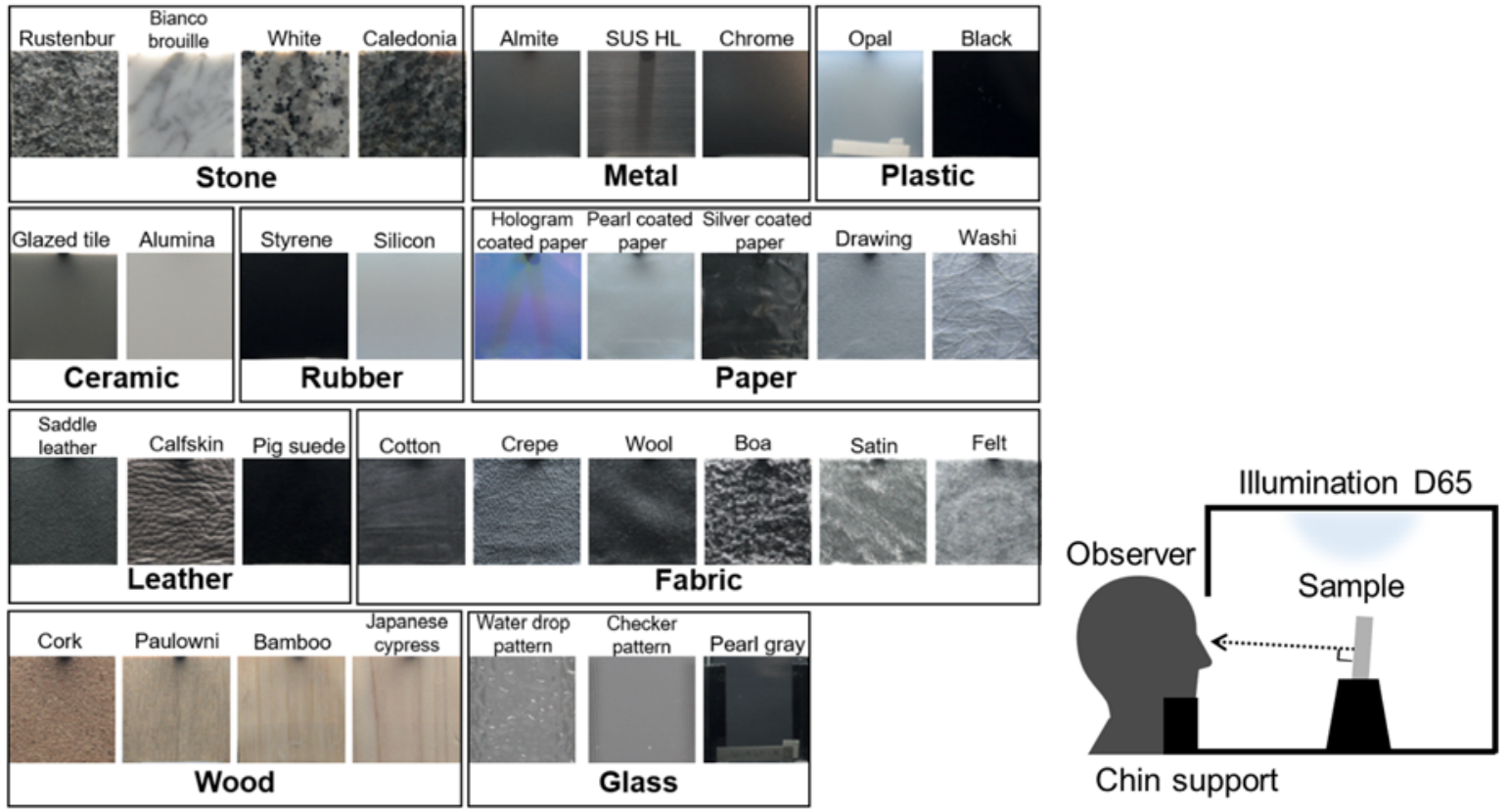

Figure 1 - Experimental material dataset

Figure 2 - Experimental environment

\section{Physical Measurements}

To obtain the physical characteristics, we captured the images of 34 stimuli and made various optical property measurements. For the physical measurement, as listed in Table 1, we used the following six devices: a multi-angle spectrophotometer (BYK-Gardner GmbH, BYK-mac i), a digital camera (Canon, 5D Mark IV), a gonio spectrophotometer (Murakami Color Research Laboratory GSP-2), two gloss meters (Rhopoint Instruments, Rhopoint IQ-S and Canon, RA$532 \mathrm{H}$ ), and another spectrophotometer (Konica Minolta, CS-2000).

\subsection{Image Properties}

As image capturing devices, we used the multi-angle spectrophotometer and the digital camera. The image properties used for our analysis are summarized in Table 1(a). As basic properties, we investigated the statistical features in both the frequency and image domains. In our preliminary investigation, the anisotropic features in the frequency domain were found to be correlated with the psychometric evaluations (Tanaka et al., 2016, 2017). Therefore, we analysed the anisotropic features in the frequency domain. We also applied the Laplacian filter to obtain the edge intensity of texture information. In addition to analysing their textures, we captured the images of real materials with white and black backgrounds to detect the light transmitted through the materials (which indicates transparency). 


\subsection{Optical Properties}

As measurement devices to investigate optical properties, we used five devices, excluding the digital camera. The image properties used for our analysis are summarized in Table 1(b). As basic properties, we investigated the statistical features from the bidirectional reflectance distribution function (BRDF), because spatial changes in the reflection produced by minute unevenness of the surface can affect judgments of perceptual appearance. We also measured properties such as gloss scale, haze, and distinctness of image (DOI), which can be measured with a standard gloss meter. In addition to the above reflectance property, we also measured the luminance for each stimulus with different white and black backgrounds.

Table 1 - List of Devices and Measured Physical Properties

(a) Image properties

\begin{tabular}{|l|l|}
\hline \multicolumn{1}{|c|}{ Device } & \multicolumn{1}{|c|}{ Property } \\
\hline Multi-angle \\
spectrophotometer \\
BYK-mac i
\end{tabular}$\quad \begin{aligned} & \text { Condition: (Diffused, A-normal }-15^{\circ}, 45^{\circ}, 75^{\circ} \text { ) } \\
& \text { - Anisotropy histogram: Skewness, Kurtosis, Variance, Average } \\
& \text { - Grey histogram: Skewness, Kurtosis, Standard deviation }\end{aligned}$

(b) Optical properties

\begin{tabular}{|l|l|}
\hline \multicolumn{1}{|c|}{ Device } & \multicolumn{1}{c|}{ Property } \\
\hline $\begin{array}{l}\text { Multi-angle } \\
\text { spectrophotometer } \\
\text { BYK-mac i }\end{array}$ & $\begin{array}{l}\text { Condition: (incident angle (A-normal) }-45^{\circ} \text {, acceptance angle (A- } \\
\left.\text { normal) } 60^{\circ}, 30^{\circ}, 20^{\circ}, 0^{\circ},-30^{\circ},-65^{\circ}\right) \\
\text { - BRDF histogram: Skewness, Kurtosis, Standard Deviation }\end{array}$ \\
\hline $\begin{array}{l}\text { Gonio spectrophotometer } \\
\text { GSP-2 }\end{array}$ & $\begin{array}{l}\text { Condition: (incident angle }-50^{\circ} \sim+50^{\circ} \text { (in } 10^{\circ} \text { steps), acceptance } \\
\left.\text { angle } 0^{\circ}\right) \\
- \text { BRDF histogram: Skewness, Kurtosis, Standard Deviation }\end{array}$ \\
\hline $\begin{array}{l}\text { Gloss meter } \\
\text { Rhopoint IQ-S }\end{array}$ & $\begin{array}{l}\text { Gloss scale }\left(20^{\circ}, 60^{\circ}, 85^{\circ}\right), \text { Haze, LogHaze, DOI, Peak specular } \\
\text { reflectance (Rspec), Reflected image quality (RIQ) }\end{array}$ \\
\hline $\begin{array}{l}\text { Gloss meter } \\
\text { RA-532H }\end{array}$ & $\begin{array}{l}\text { Gloss scale }\left(20^{\circ}, 60^{\circ}, 85^{\circ}\right), \text { Specular width (C20, C60), Haze, } \\
\text { DOI, BRDF volume }\left(20^{\circ}, 60^{\circ}\right), \text { BRDF intensity }\left(20^{\circ}, 60^{\circ}\right)\end{array}$ \\
\hline $\begin{array}{l}\text { Spectrophotometer } \\
\text { CS-2000 }\end{array}$ & Luminance (Black and white backgrounds) \\
\hline
\end{tabular}

\section{Relationships between Physical Properties and Perceptual Appearance}

The significance of the psychometric evaluations for each stimulus was verified using a t-test after excluding the outlier data using the Smirnoff-Grubbs test. The correlations between the psychometric evaluations and the physical characteristics were calculated, and the following strong correlations were confirmed for each appearance factor.

- Perceptual gloss was strongly correlated with the gloss unit (GU) scale measured by the gloss meters and the BRDF statistics measured by the Gonio photometer. 
- Perceptual transparency was strongly correlated with the luminance difference of real materials and the variance of anisotropy histogram obtained from the difference images between black and white backgrounds.

- Perceptual roughness was strongly correlated to the edge intensity of the captured image. In addition, the skewness and the standard deviation of the grey histogram had significant correlation.

From these findings, we further considered describing the psychometric evaluations of perceptual appearance from the most correlated physical properties.

\subsection{Glossiness}

We define the normalized psychometric assessment value of glossiness as "Perceptual Gloss $(P G), "$ which is given as follows:

$$
\text { Perceptual Gloss }[\mathrm{PG}]=\alpha(\text { Physical Gloss })^{m}[\mathrm{GU}]
$$

where

$\alpha$ : Normalization factor,

Physical Gloss: Maximum value among physical gloss $\left\{\right.$ Gloss $\left.20^{\circ}, 60^{\circ}, 85^{\circ}\right\}$ (ISO2813),

$m$ : Multiplier factor $(m=0.58)$.

The correlation for the 34 stimuli is shown in Fig. 3(a). By using the maximum physical gloss scale among three measurement angles $\left(20^{\circ}, 60^{\circ}, 85^{\circ}\right)$ based on ISO2813 as 'physical gloss', the correlation was best with perceptual gloss evaluations $\left(R^{2}=0.724\right)$. Stimuli that could not be estimated with sufficient accuracy were glasses, fabrics, and stones that have transparency and roughness as well as glossiness.

\subsection{Transparency}

"Perceptual Transparency (PT)" was defined as the psychometric assessment value of transparency using the physical measurements data as follows:

Perceptual Transparency $[\mathrm{PT}]=\alpha(\text { Luminance Difference })^{m}$

where

$\alpha$ : Normalization factor,

Luminance Difference: Luminance difference with white vs black backgrounds,

$m$ : Multiplier factor $(m=0.60)$.

The correlation for the 34 stimuli is shown in Fig. 3(b). We confirmed that the correlation between PT and the characteristics of physical measurement was very high $\left(R^{2}=0.938\right)$.

\subsection{Roughness}

We define "Perceptual Roughness (PR)" as the psychometric assessment value of roughness by using the physical measurements data such as texture characteristics as follows:

Perceptual Roughness $[\mathrm{PR}]=\alpha\left(\right.$ Texture ${\text { Characteristic })^{m}}^{m}$

where

$\alpha$ : Normalization factor,

Texture Characteristic: Edge intensity using the Laplacian filter,

$m$ : Multiplier factor $(m=0.39)$.

The perceptual roughness was estimated by applying the Laplacian filter to a captured grayscale image. The correlation for the 34 stimuli is shown in Fig. 3(c). We confirmed a high correlation for PR $\left(R^{2}=0.741\right)$, but four data stood apart from the linearization line. The material categories of these outliers were glass, stone, and fabric, and they had very uneven surfaces as a common characteristic. 


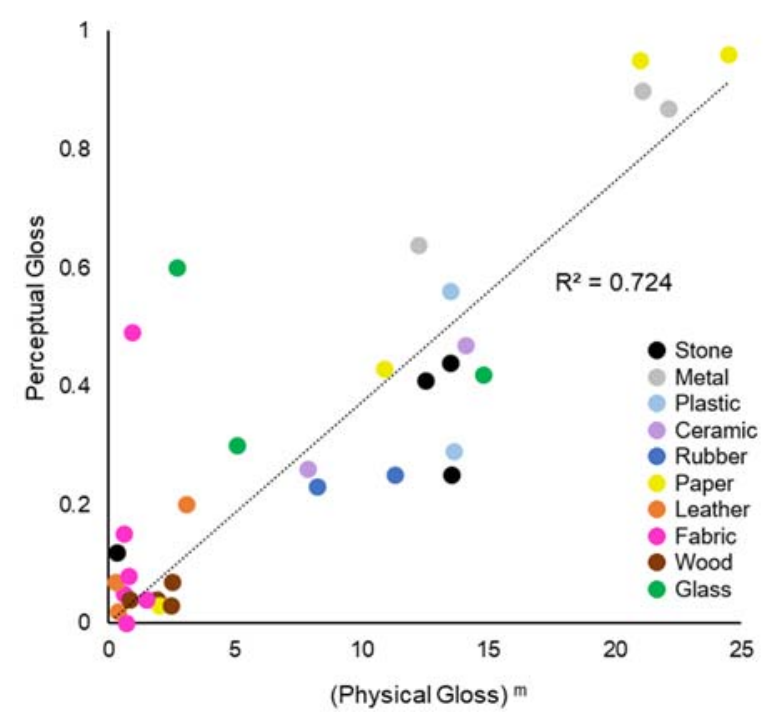

(a) Glossiness

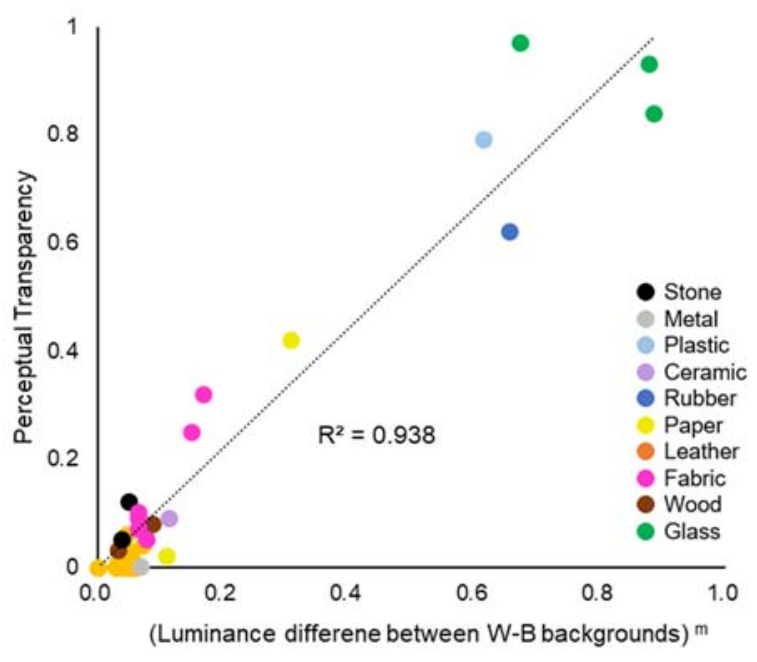

(b) Transparency

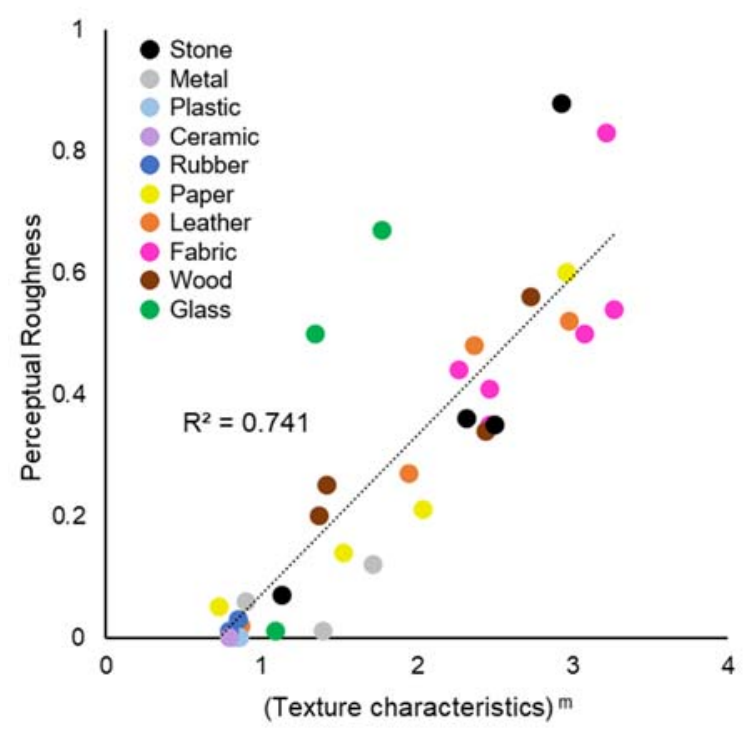

(c) Roughness

Figure 3 - Relationship between physical values and perceptual appearance

\section{Conclusion}

In this study, we found effective indices for representing material appearance by analysing the relationship between the physical data and the perceptual appearance. In our physical measurements and subjective evaluations, we used various materials comprising ten material categories to describe the three appearance factors of glossiness, transparency, and roughness. As a result, we observed physical indices for describing each appearance factor as follows: (1) The index of perceptual gloss corresponded to a nonlinear transform of physical glossiness. (2) The index of perceptual transparency corresponded to the luminance difference of material surface upon white and black backgrounds. (3) The index of perceptual roughness was correlated to the edge intensity detected from the captured images. The estimate of each appearance factor will be further improved obtaining further experimental data in the future. Our results indicate that it may be possible to construct a total appearance model representing not only colour but also multiple appearance factors such as glossiness and roughness. 


\section{References}

ALBERTAZZI, L. \& HURLBERT, A. 2013. The Perceptual Quality of Color. In M. Mirmehdi, Albertazzi, L. (Eds.), Handbook of Experimental Phenomenology: Visual Perception of Shape, Space and Appearance (section 15). John Wiley \& Sons.

FLEMING, R. W., DROR, R. O., \& ADELSON, E. H. 2003. Real-world illumination and the perception of surface reflectance properties. Journal of Vision, 3, 347-368.

FLEMING, R. W., \& BÜLTHOFF, H. H. 2005. Low-level image cues in the perception of translucent materials. ACM Transactions on Applied Perception, 2(3), 346-382.

FLEMING, R. W., WIEBEL, C., \& GEGENFURTNER, K. 2013. Perceptual qualities and material classes. Journal of Vision, 13(8), 9.

MOTOYOSHI, I., \& MATOBA, H. 2012. Variability in constancy of the perceived surface reflectance across different illumination statistics. Vision Research, 53, 30-39.

MOTOYOSHI, I. 2010. Highlight-shading relationship as a cue for the perception of translucent and transparent materials, Journal of Vision, 10(9), 1-11.

NISHIDA, S., \& SHINYA, M. 1998. Use of image-based information in judgments of surfacereflectance properties. Journal of the Optical Society of America, 15, 2951-2965.

PADILLA, S., DRBOHLAV, O., GREEN, P. R., SPENCE, A. D., \& CHANTLER, M. J. 2008. Perceived roughness of $1 / \mathrm{f}$ noise surfaces. Vision Research, 48, 1791-1797.

PONT, S. C., \& KOENDERINK, J. J. 2005. Bidirectional texture contrast function. International Journal of Computer Vision, 62(1/2). April/May 2005, special issue on Texture Synthesis and Analysis.

PONT, S. C., \& KOENDERINK, J. J. 2008. Shape, surface roughness, and human perception. In M. Mirmehdi, X. Xie, \& J. Suri (Eds.), Handbook of texture analysis (pp. 197-222). Imperial College Press.

TANAKA, M., \& HORIUCHI, T. 2015. Investigating perceptual qualities of static surface appearance using real materials and displayed images, Vision Research, 115(B), 246-258.

TANAKA, M., \& HORIUCHI, T. 2016. Appearance harmony of materials using real objects and displayed images. Journal of the International Colour Association, 15, 3-18.

TANAKA, M., \& HORIUCHI, T. 2017. Physical Indices for Judging Appearance Harmony of Materials, Color Research and Application, 42(6), 788-798. 